\title{
O Papel da Escolha do Mecanismo de Coordenação na Performance da Cadeia de Produção Avícola de Pernambuco
}

\author{
Juliana Matos de Meira \\ Mestrado em Contabilidade pela UNB/UFPB/UFPE/UFRN \\ R. Gal Salgado, 235/1203. Boa Viagem. Recife/PE. CEP: 51130-320 \\ E-mail: juliana1404@hotmail.com
}

Cláudio de Araújo Wanderley Mestrado em Engenharia de Produção pela Universidade Federal de Pernambuco UFPE R. Gal Salgado, 235/1203. Boa Viagem. Recife/PE. CEP: 51130-320 E-mail: claudiowanderley@hotmail.com

Luiz Carlos Miranda

Ph.D. pela University of Illinois R. João Fragoso de Medeiros, 34/101. Candeias. Jaboatão/PE. CEP: 54.430-250

E-mail: Ic-miranda@uol.com.br

\section{RESUMO}

Este trabalho tem como objetivo verificar qual o papel da escolha do mecanismo de coordenação para o desempenho da cadeia de produção avícola de Pernambuco. Foram realizadas 38 entrevistas com produtores que atuam através de diferentes mecanismos de coordenação desenvolvendo atividades na cadeia de produção de frango de corte do Estado de Pernambuco. Com a pesquisa realizada, observou-se que a escolha do mecanismo de coordenação é um fator que influencia, ainda que parcialmente o desempenho dos produtores desta cadeia.

Palavras-Chave: Performance. Mecanismos de coordenação. Cadeia de produção avícola.

The Role of the Choice of Coordination Mechanism on Performance in Pernambuco's Poultry Supply Chain

\section{ABSTRACT}

The purpose of this paper is to verify the role of coordination mechanism choice on performance in Pernambuco's poultry supply chain. Thirty eight interviews were conducted with poultry producers, who act in the supply chain through different coordination mechanism, developing activities regarding chicken production. The results show that the coordination choice has some influence on the performance of Pernambuco's poultry supply chain producers. 
O Papel da Escolha do Mecanismo de Coordenação na Performance da Cadeia de Produção Avícola de Pernambuco Juliana Matos de Meira, Cláudio de Araújo Wanderley, Luiz Carlos Miranda

Key words: performance measurement, coordination choice, poultry supply chain.

\section{INTRODUÇÃO}

Após a Revolução Industrial, durante o século XIX, existiram grandes empresas que estavam estruturadas de forma bastante verticalizada, executando boa parte das atividades da cadeia produtiva. As mudanças tecnológicas, sociais e econômicas provocaram o surgimento de novas demandas, afetando o perfil dos consumidores de produtos e serviços, que estão cada vez mais exigentes. A coordenação das atividades econômicas passou a ser feita também através do mercado, provocando o surgimento de uma variedade de empresas que atuam apenas em parte das atividades de sua cadeia produtiva.

Neste novo ambiente empresarial, para assegurar sua competitividade, a empresa deve ser vista apenas como parte (elo) de sua cadeia de produção ou cadeia de valor, como estabelecido no modelo do SCM - Supply Chain Management (Gerenciamento de Cadeias de Produção). Este modelo pressupõe que diante das imperfeições do mercado, maximizar a eficiência das atividades internas de elos isolados da cadeia de valor não é suficiente. É necessário que a organização tenha um relacionamento com as demais empresas que executam as atividades relevantes de sua cadeia, visando obter a eficiência da cadeia como um todo.

Dessa forma, surge a coordenação via informação, que se situa entre a coordenação vertical (ou via hierarquia) e a coordenação horizontal (ou via mercado), visando maximizar a criação de valor ao longo da cadeia produtiva através da troca de informações interorganizacionais de forma organizada e estruturada.

A escolha do mecanismo de coordenação pode ter influência sobre a performance das empresas de uma cadeia produtiva, como revelado pelo estudo de Miranda (1997), desenvolvido no setor do agronegócio, mais especificamente, na cadeia de produção de suínos dos Estados Unidos da América. 
O Papel da Escolha do Mecanismo de Coordenação na Performance da Cadeia de Produção Avícola de Pernambuco Juliana Matos de Meira, Cláudio de Araújo Wanderley, Luiz Carlos Miranda

Para verificar qual o papel da escolha do mecanismo de coordenação para o desempenho do agronegócio brasileiro, este trabalho mostra parte dos resultados da pesquisa desenvolvida por Meira (2002) em sua dissertação de mestrado, a qual replicou a pesquisa desenvolvida por Miranda (1997) no setor avícola de Pernambuco.

A cadeia de produção avícola de Pernambuco foi escolhida devido à sua importância para a economia do Estado. De acordo com as estatísticas divulgadas no ANUALPEC - Anuário da Pecuária Brasileira (2001), o Brasil ocupa o 2o lugar na produção mundial de carne de frango, estando prevista a participação em 80,42\% da produção da América do Sul e por $14,39 \%$ da produção mundial para o ano de 2001. O Estado de Pernambuco é responsável por cerca de $50 \%$ da produção do Nordeste, sendo o $1^{\circ}$ colocado nesta região e o 6ำ colocado no ranking nacional.

$O$ crescimento do consumo de frangos vem se desenvolvendo desde o início da década de 80, quando o Brasil passou a segundo produtor mundial (AZEVEDO, 1997) posição que ocupa atualmente. De acordo com o ANUALPEC (2001), estimase que a produção em

2001 tenha sido de 6.153 mil toneladas prontas para consumo, o que representa quase a metade da produção dos Estados Unidos da América (14.208 mil toneladas). A previsão é de que, neste ano, o País tenha sido responsável por cerca de $15 \%$ da produção mundial total. A previsão para 2002 é de que essa posição seja mantida.

Para a coleta de dados foi realizada uma pesquisa empírica junto aos produtores de frango de corte do Estado de Pernambuco, através de entrevistas pessoais realizadas no período de maio a julho de 2002. Foram entrevistados 17 produtores da lista de associados da AVIPE, sendo quatro produtores independentes, 12 integradores e um integrado. Além desses produtores, foram entrevistados mais 21 produtores que não são associados da AVIPE, ou que o fazem de forma indireta, como é o caso dos integrados. Dentre os produtores que não constavam na lista da AVIPE, foram entrevistados dois produtores independentes, dois integradores e 17 integrados. A amostra resultou num total de 
O Papel da Escolha do Mecanismo de Coordenação na Performance da Cadeia de Produção Avícola de Pernambuco Juliana Matos de Meira, Cláudio de Araújo Wanderley, Luiz Carlos Miranda

38 produtores, cujos totais de cada grupo estão apresentados a seguir:

Tabela 1. Respondentes por grupos de produtores

\begin{tabular}{|c|c|c|}
\hline Grup & Quant & Percent \\
\hline Produtores independentes & 06 & $16 \%$ \\
\hline Produtores integradores & 14 & $37 \%$ \\
\hline Produtores integrados & 18 & $47 \%$ \\
\hline Total & 38 & $100 \%$ \\
\hline
\end{tabular}

Apesar da amostra ter sido selecionada por conveniência, devido às dificuldades de acesso aos produtores, somando-se a produção dos produtores independentes e dos integradores (aqui incluída a produção dos respectivos integrados), obtém-se um total de aproximadamente 66.000 .000 de frangos de corte por ano, o que representa cerca de $56 \%$ da produção total do Estado de Pernambuco (177.204.000 aves), com base no ano de 2001.

O trabalho está estruturado em sete seções, além desta introdução: Mecanismos de Coordenação, Cadeia de Produção Avícola, Coordenação na Avicultura, Avaliação de Performance no Setor Avícola, Análise dos Resultados e Considerações Finais. A primeira seção explica os mecanismos de coordenação via hierarquia, via mercado e via informação. A seção seguinte descreve as principais atividades da cadeia de produção de frango de corte. Em seguida, são expostos os mecanismos de coordenação mais utilizados no setor avícola e depois são apresentados os principais índices de avaliação de desempenho utilizados no setor avícola e são mostrados os resultados da pesquisa realizada. Por último, são apresentadas as conclusões.

\section{MECANISMOS DE COORDENAÇÃO}

A forma de atuação na cadeia de produção depende da escolha do mecanismo de coordenação das atividades a serem desenvolvidas pelas empresas. Ao participar de uma cadeia de produção, dentre outras decisões estratégicas que uma empresa tem que tomar, está a escolha das atividades que 
O Papel da Escolha do Mecanismo de Coordenação na Performance da Cadeia de Produção Avícola de Pernambuco Juliana Matos de Meira, Cláudio de Araújo Wanderley, Luiz Carlos Miranda

irá executar e coordenar. De acordo com Miranda (1997, p.26), coordenação é o processo através do qual participantes de um setor produtivo organizam as atividades de sua cadeia, tais como, produção, processamento, distribuição e consumo.

As formas de coordenação das atividades econômicas também são conhecidas como estruturas de governança. Miranda (2002, p. 205) aborda que os dois principais mecanismos para coordenar as atividades de uma empresa são: coordenação via mercado, que é uma forma de coordenação horizontal e coordenação via hierarquia, que é uma forma de coordenação vertical. Entre esses dois extremos existem inúmeros mecanismos de coordenação possíveis, que se referem às estruturas híbridas e também são formas de coordenação vertical. A escolha desses mecanismos intermediários vai depender, entre outras coisas, da quantidade de informação requerida e do custo de obtenção da mesma.

De acordo com Lazzarini e Giordano (1996, p. 1086-1087), na coordenação através do mercado ou coordenação horizontal, partes autônomas realizam as transações sem haver desejo do estabelecimento de laços contratuais de longo prazo. A coordenação realizada por meio de hierarquias também é denominada integração vertical e ocorre quando dois estágios da produção unem-se em uma única firma. As formas híbridas mesclam parte da característica de mercado, pois as partes envolvidas são firmas distintas e parte da característica da integração vertical, pois existe um sistema de controle e busca-se promover a continuidade das transações. Machado (1998, p. 67) acrescenta que nas empresas dos sistemas agroindustriais as estruturas híbridas são cada vez mais comuns.

\subsection{Coordenação via mercado}

A coordenação via mercado é a forma mais tradicional e é feita por meio do sistema de informações baseado nos preços verificados no mercado. Cada empresa da cadeia de produção vai ao mercado e informa o preço que está disposta a pagar pelos insumos de que necessita, e o preço que aceita receber para vender 
O Papel da Escolha do Mecanismo de Coordenação na Performance da Cadeia de Produção Avícola de Pernambuco Juliana Matos de Meira, Cláudio de Araújo Wanderley, Luiz Carlos Miranda

seus produtos ou serviços.

A forma que privilegia o mercado tem sua origem na obra de Adam Smith de 1776, com a proposição básica de que o mercado, como uma "mão invisível", direciona os recursos no sistema econômico, de forma eficiente e descentralizada, com o sistema de preços funcionando de modo tal que o ajuste entre oferta e demanda é automático.

Williamson (in Miranda 1997, p. 29) menciona que o mercado é o modo normal de organização, mas para neutralizar custos devidos às ineficiências das transações realizadas via mercado, surgem as coordenações via hierarquias. Esses custos são chamados de custos da transação e podem ser ex ante, tais como: custos de coleta de informação no mercado e custos de negociação e estabelecimento de um contrato com outras empresas. Ou então ex post, que estão associados ao acompanhamento da execução de acordos, ajustamentos em decorrência de falhas ou defesas por quebra de contratos (Coase in Machado, 2000).

\subsection{Coordenação via hierarquia}

A coordenação das atividades econômicas via hierarquia é aquela feita dentro da firma. Substitui-se o mecanismo de coordenação via mercado - o preço por mecanismos baseados no controle e na burocracia. Williamson (in Jank, 1996, p. 36) explica que este tipo de coordenação está baseado no "controle hierárquico gerencial de estágios sucessivos de produção, tecnologicamente separáveis entre si”.

De acordo com Miranda (2002, p. 205-206), a coordenação via hierarquia surge devido às imperfeições do mercado, onde as informações estão distribuídas de forma assimétrica. Nesse caso, ao invés de negociar com seus fornecedores ou clientes via preço, a empresa prefere expandir suas fronteiras incluindo os mesmos, ocorrendo, então, a integração vertical.

Slack et al. (1997, p. 183) afirmam que, em sentido estratégico, a integração vertical envolve a análise da conveniência de uma empresa adquirir fornecedores 
O Papel da Escolha do Mecanismo de Coordenação na Performance da Cadeia de Produção Avícola de Pernambuco Juliana Matos de Meira, Cláudio de Araújo Wanderley, Luiz Carlos Miranda

e/ou clientes. Porter (1986, p. 278-279) explica que integração vertical "é a combinação de processos de produção, distribuição, vendas e/ou outros processos econômicos tecnologicamente distintos dentro das fronteiras de uma mesma empresa. Isto representa, portanto, uma decisão da empresa no sentido de utilizar transações internas ou administrativas em vez da utilização de transações de mercado".

O autor acrescenta que a decisão de "fazer ou comprar" não deve ser baseada nos cálculos de economias de custos, mas devem ser considerados os problemas estratégicos mais amplos da integração, em comparação com o uso de transações de mercado, bem como problemas administrativos que surgem na gestão de uma entidade integrada verticalmente e que podem afetar o sucesso desta empresa. Esses problemas são estudados pela teoria do agenciamento, mas são dificilmente quantificáveis.

Segundo Beccerra e Gupta (1999, p. 182), o objetivo da teoria do agenciamento é desenhar um contrato que minimize os custos das relações dos agentes com o principal, também conhecidos como custos do agenciamento. Miranda (1997, p. 31) explica que o principal é o dono, o gerente ou o diretor financeiro, que delegam ativos para outras pessoas operarem. $O$ agente é o gerente ou o empregado, que atuam em benefício do principal. E acrescenta que no centro da teoria do agenciamento está o fato de que os agentes podem ter interesses diferentes dos do principal.

Como pode ser observado, se a empresa optar pela coordenação via mercado tem que gerenciar os custos da transação e se escolher a coordenação vertical, tem que controlar os custos do agenciamento. Por isso, muitas empresas têm mesclado essas alternativas e operam com as chamadas estruturas híbridas, o que pode ser confirmado na seguinte afirmação de Shank e Govindarajan (1997, p. 62): "não conhecemos nenhuma empresa que atravesse toda a cadeia de valor em que opera". Este seria o caso de total integração vertical. Os autores acrescentam que não é possível ignorar as ligações da cadeia de valor. É necessário conhecer sua estrutura e dividi-la em atividades estratégicas relevantes, a fim de se 
O Papel da Escolha do Mecanismo de Coordenação na Performance da Cadeia de Produção Avícola de Pernambuco Juliana Matos de Meira, Cláudio de Araújo Wanderley, Luiz Carlos Miranda

compreender o comportamento dos custos e as fontes de diferenciação.

\subsection{Coordenação via informação}

Segundo Miranda (2002, p. 206), devido à constante busca de novas alternativas para reduzir custos e diferenciar seus produtos, ampliadas pelas oportunidades proporcionadas pelos avanços da tecnologia da informação e comunicação, as empresas desenvolveram novas formas de coordenação, superiores às coordenações via mercado e via hierarquia. Trata-se da coordenação via informação, que se situa entre os dois extremos (coordenação via mercado e coordenação via hierarquia), como pode ser observado na Figura 1.

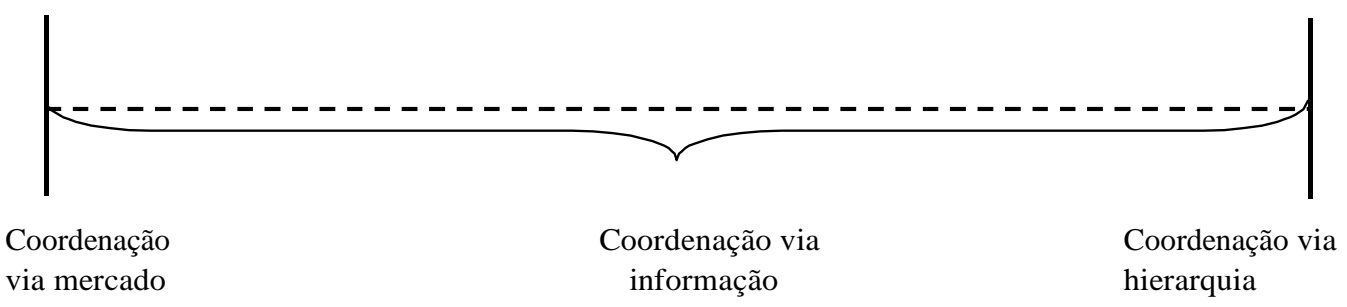

Figura 1. Mecanismos de coordenação

Fonte: Meira (2002) 
Este novo tipo de coordenação utiliza estruturas de governança híbridas, pois não há controle de propriedade entre as partes e a coordenação baseia-se na troca de informações. Sobre as estruturahíbridas, Furlanetto (2000, p. 3) assinala que as empresas administram suas dependências externas através da construção de "pontes" (alianças) com outras organizações, alterando a fronteira das organizações, tanto por meios formais como informais. $E$ acrescenta que há uma variedade muito grande de estratégias interorganizacionais que compõem esses tipos de estruturas, tais como: alianças, parcerias formais e informais, joint-ventures.

O autor denomina este tipo de coordenação vertical de "coordenação pela cadeia de produção". E explica que, como a empresa não dispõe de todos os recursos, tais como informações sobre o mercado, ela constrói pontes com outras empresas, ou seja, procura interagir com o ambiente a seu favor, buscando reduzir os custos da transação. Em consonância, Barut, Faisst e Kanet (2002) afirmam que a integração entre empresas e a coordenação através da tecnologia da informação tornou-se um aspecto chave para melhoria da performance da cadeia produtiva. Esse tipo de integração é chamado de integração logística por Christopher (1999, p. 206).

O aumento do volume de informações compartilhadas pelas empresas nessas estruturas híbridas permite a redução dos custos da transação. De acordo com Miranda (1997, p.30), esta é a ligação entre a teoria dos custos da transação e o compartilhamento de informações interorganizacionais.

O SCM - Supply Chain Management (Gerenciamento de Cadeias de Produção) é um modelo de gestão empresarial que pode ser utilizado no contexto da coordenação via informação. Este modelo vem sendo estudado por especialistas (Miranda, 1997, 2002; Souza et al., 2000; Furlanetto, 2000; Souza, 1999; Riggs e Robbins, 1998; Copacino, 1997; Poirier e Reiter, 1996; Billington, 1994) e busca a ampliação do foco da gestão para além da fronteira legal das empresas, incluindo atividades das demais empresas da cadeia produtiva.

\section{CADEIA DE PRODUÇÃO AGRÍCOLA}

Vocht (1996, p. 41) separa a cadeia avícola em cadeias de produção e 
distribuição de frangos de corte. A primeira é representada pela cadeia biológica, onde ocorre a seleção genética e o ciclo de evolução dos frangos de corte, e pela cadeia de nutrição, onde são estudados os principais componentes da ração. $A$ segunda cadeia, a de distribuição, divide-se em distribuição de frangos vivos e distribuição de frangos abatidos. Vocht (1996, p.43-45) divide a cadeia biológica de frangos de corte em quatro participantes: a granja avozeira, a granja de matrizes, o incubatório e a granja de engorda de aves.

As granjas avozeiras estabelecidas no Brasil obtêm seu plantel através de importação de aves avós, pois a tecnologia para desenvolver as avozeiras é um segredo industrial de empresas geneticistas estrangeiras. O objetivo desta atividade, de acordo com Luce e Karsten (in Souza et al., 2000, p. 82) é a criação de novas variedades de aves, buscando uma maior produtividade.

Através de cruzamentos entre as aves avós importadas, são obtidas as linhagens genéticas de aves matrizes direcionadas para a produção de frangos de corte, tais como Hubbard, Ross, Cobb, Arbo-acres, Avifarmes. De acordo com Nascimento (1986, p. 16), linhagem representa uma "população de indivíduos que apresentam características comuns".

As granjas de aves matrizes produzem ovos férteis, que, por sua vez, vão para os incubatórios onde ocorre a eclosão em chocadeiras elétricas e o nascimento dos pintos de um dia. Esses pintos são levados para as granjas de engorda onde são preparados para o abate. Além do recebimento dos pintos de um dia e da criação dos frangos de corte, a granja de engorda desenvolve a atividade de preparação dos galpões para repovoamento de pintos de um dia, que consiste em: retirar o subproduto esterco deixado nos aviários; lavar, limpar e desinfetar os galpões e equipamentos; deixar em repouso por alguns dias (tempo de vazio sanitário); e montar novamente os equipamentos para recepção do novo lote de pintos de um dia.

Na cadeia de nutrição, Vocht (1996, p. 55-68) inclui: o plantio da soja e do milho; a fabricação da ração, feita através do processamento do milho, da soja e de outros componentes; e a nutrição dos frangos de corte, que é realizada nas granjas de engorda. $\mathrm{O}$ autor destaca que o item ração representa aproximadamente $70 \%$ 
dos custos de produção dos frangos de corte, o que reforça a importância das atividades relativas à nutrição na avicultura.

Uma vez prontos para o abate, os frangos de corte são levados das granjas de engorda para pequenos varejistas ou para abatedouros industriais. De acordo com Vocht (1996, p. 86-114), os pequenos varejistas vendem tanto as aves vivas como abatidas, através de um abate artesanal no próprio ponto de venda. $\mathrm{E}$ a distribuição dos frangos abatidos é feita para supermercados e mercearias, que comercializam para o consumidor final. As aves abatidas podem ser comercializadas resfriadas ou congeladas, inteiras ou em partes.

Outros autores como Marques (1991, p. 5) e Costa (1999, p. 27-28), descrevem a cadeia de produção avícola de forma semelhante, com diversas atividades. Estas atividades devem ser coordenadas através da troca de informações entre os elos da cadeia para permitir um eficaz gerenciamento da mesma. A Figura 2, apresentada a seguir, mostra a cadeia de produção avícola completa, e os fluxos de informações, insumos e produtos entre seus elos, representados pelas setas: 


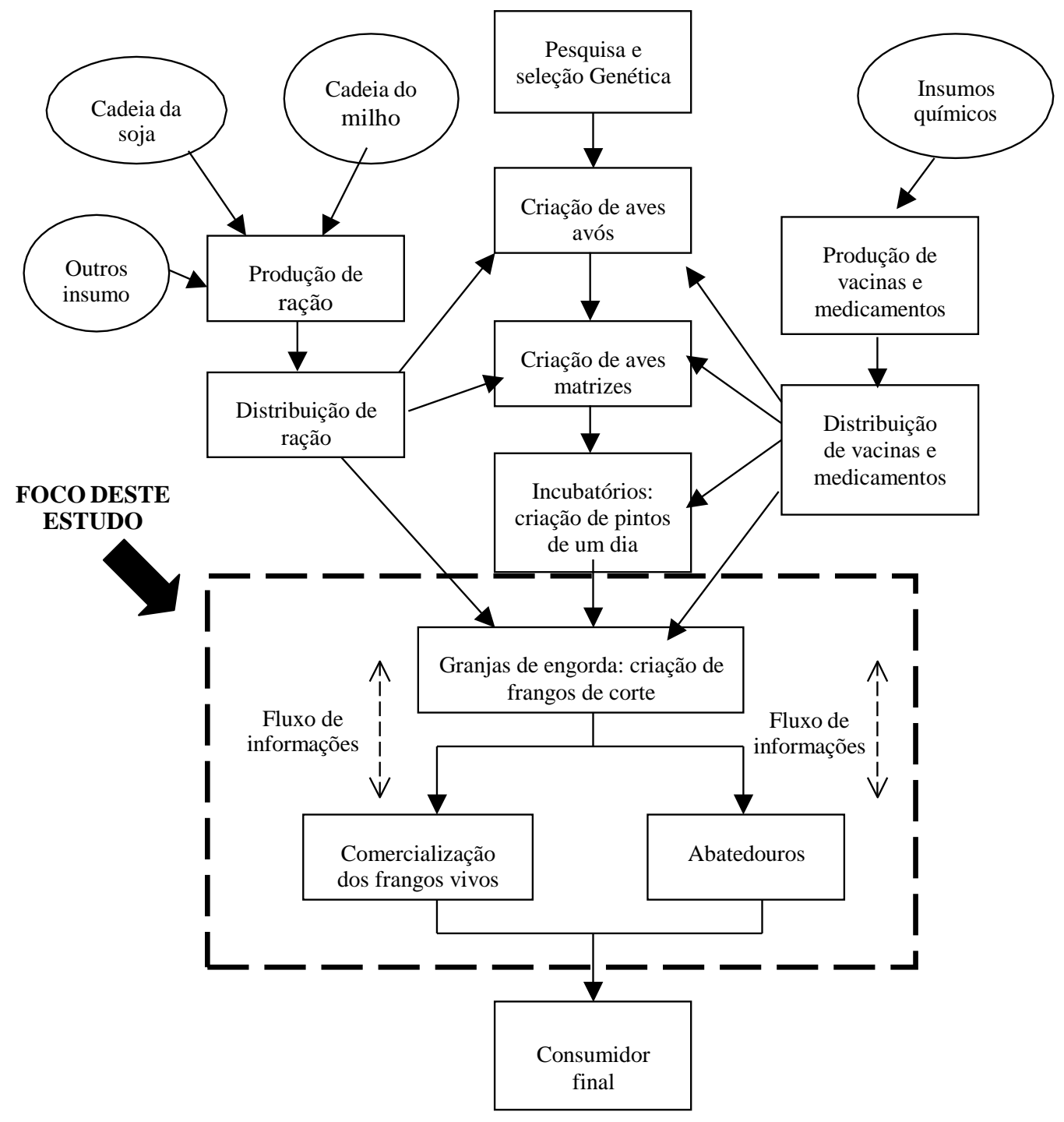

Figura 2. Cadeia de produção avícola Fonte: Meira (2002)

\section{COORDENAÇÃO NA AVICULTURA}

A seguir são descritas as principais características dos diferentes tipos de produtores da cadeia avícola e os respectivos mecanismos de coordenação normalmente utilizados pelos mesmos:

Produtor independente - é o produtor que desenvolve apenas a atividade de criação de frangos de corte, utilizando a coordenação via mercado para adquirir 
insumos e comercializar as aves. Este tipo de produtor pode também desenvolver outras atividades dentro de uma única firma, passando a coordenar via hierarquia. As atividades normalmente desenvolvidas por esses produtores são: produção de ração, produção de aves matrizes, incubação de pintos, produção de frangos de corte e comercialização de aves vivas (para intermediários, pequenos varejistas ou até mesmo para os abatedouros industriais do segmento formal). Caso exerça também a atividade de abate, pode comercializar seus frangos abatidos para o varejo.

Integrador - além das atividades desenvolvidas dentro da firma, tais como produção de aves matrizes, de ração, incubação de pintos e produção frangos de corte em granjas próprias (coordenação via hierarquia), o integrador atua em parceria com produtores integrados, que realizam apenas a atividade de criação dos frangos de corte (coordenação via informação). Para tanto, o integrador é responsável pela compra dos insumos, assistência técnica ao criador (integrado) e comercialização das aves. O integrador pode possuir também o abatedouro industrial, cujos abates são realizados sob Inspeção Estadual e Federal, dentro do segmento formal.

Produtor integrado - é o produtor que atua de forma conjunta com o integrador e tem como atividade principal o manejo (criação) das aves. É responsável pelas instalações físicas e pelos cuidados com as aves. No entanto, não participa da compra dos insumos, nem da comercialização das aves.

\section{AVALIAÇÃo DE PERFORMANCE NO SETOR AVÍCOLA}

Para avaliar a performance dos produtores, foram escolhidos índices técnicos que são largamente utilizados para medir o desempenho da produção de frango de corte, conforme descrito a seguir:

- Conversão alimentar = Consumo de ração/peso da ave

- Ganho de peso diário = Peso da ave/idade da ave

- Taxa de mortalidade = Número de aves retiradas/número inicial de aves 
- Fator de produção = (Ganho de peso diário $) \times(1$-taxa de mortalidade $)$

- (Conversão alimentar) x (100)

A conversão alimentar permite saber qual foi a quantidade de ração necessária para cada quilo de ave pronta para o abate. Portanto, quanto menor for este índice, melhor, pois significa um menor consumo de ração e, consequentemente, menores custos para o produtor.

Uma maior média de ganho de peso diário nem sempre significa maior eficiência para o produtor, pois é necessário levar em consideração que um valor maior para este índice indica que a ave foi retirada com mais peso, porém, com mais idade. $\mathrm{E}$ a idade pode influenciar negativamente $\mathrm{o}$ índice de conversão alimentar, porque depois uma determinada idade o ganho de peso diário deixa de aumentar, permanecendo o mesmo por alguns dias e diminuindo depois. No entanto, o consumo de ração continua aumentando, fazendo com que a conversão alimentar fique mais elevada também.

Por exemplo, de acordo com o Manual de manejo de frangos (2000), um lote de machos e fêmeas da linhagem AgRoss 508 tem o ganho de peso diário estabilizado em 81 gramas por dia aos 41 dias. Aos 48 dias este valor começa a decrescer. Mas como o consumo de ração continua aumentando, há um aumento da conversão alimentar.

Em relação à taxa de mortalidade, quanto menor for este índice, melhor para o produtor, pois maior será a viabilidade. Esta é medida pela equação 1 - taxa de mortalidade e mostra a proporção de aves vivas no fim do lote em relação ao total de aves iniciais, ou seja, quanto do lote foi viabilizado. Consequentemente, maior será o fator de produção que é diretamente proporcional à viabilidade.

O fator de produção é um índice bastante utilizado na avicultura de corte, especialmente nas integrações. Este indicador é reflexo da qualidade do pinto, qualidade da ração e de todas as ações tomadas durante a criação do lote e, através dele, a maioria dos integradores remuneram seus integrados, pois é uma maneira prática de estabelecer critérios de remuneração. 
Mendes (1989, p. 121) explica que o fator de produção avalia de uma maneira global os outros índices, tais como viabilidade, idade de abate, peso médio da ave pronta para o abate e conversão alimentar. Esses índices são colocados na fórmula de tal maneira que no numerador apareçam todos os fatores que devem ser aumentados; e, no denominador, aqueles que devem ser diminuídos.

Conforme o Manual de manejo de frangos (2000), este índice também é conhecido com Fator de Eficiência Europeu (FEE) e quanto maior seu valor, melhor o desempenho técnico. Além disso, este índice é usado extensivamente em certos países da Europa para comparar plantéis dentro de uma integração ou país. No entanto, não pode ser usado para comparar os desempenhos entre países.

Mendes (1989, p. 121) acredita que a estrutura lógica do fator de produção não é perfeita, porque

as correlações existentes entre os diversos parâmetros da fórmula são baixas. Além disso, o fator de produção tem uma tendência de supervalorizar o ganho de peso quando, na verdade, a conversão e a mortalidade são mais importantes do ponto de vista da maximização do retorno econômico. Outra desvantagem desse índice é que o número obtido é um valor puro, sem referencial de comparação. A única coisa que sabemos é que quanto maior for esse número, melhor será o resultado.

Sobre a melhor forma de avaliar o desempenho na avicultura, Mendes (1989, p. 124) afirma que "o índice perfeito de avaliação do desempenho produtivo seria aquele que conseguisse ordenar os parâmetros de avaliação de maneira que o melhor lote, tecnicamente falando, apresentasse o melhor índice e fosse, também, o mais lucrativo".

No entanto, o autor lembra que "na prática, esse índice não existe, pois a relação dos preços dos insumos avícolas e do produto final é muito variável. Portanto, resta a cada empresa escolher um índice que permita avaliar o desempenho técnico e tentar correlacioná-lo com o desempenho econômico". Sobre o desempenho econômico, o autor comenta que muita importância é dada ao ganho de peso, mas enfatiza que estudo desenvolvido por Masic \& Pavlovski mostra uma correlação muito baixa deste parâmetro com o desempenho econômico. 
Este estudo analisa os resultados de seis testes de desempenho realizados na lugoslávia, envolvendo cinco linhagens de frango de corte.

Os resultados evidenciam que, dentre os índices de ganho de peso, mortalidade e conversão alimentar, esta última representa o parâmetro mais importante para a avaliação do desempenho econômico, pois apresenta maior correlação com o resultado econômico. Em consonância com esses resultados, Mendes (1989) enfatiza que a eficiência da transformação da ração em carne é mais importante que a velocidade do processo de transformação (peso médio, tempo de produção do lote e ganho de peso diário), pois a ração representa cerca de $70 \%$ do custo de produção.

Mendes (1989, p.126) faz uma análise crítica dos resultados de desempenho da avicultura, onde constata que para avaliar os resultados de uma empresa avícola deve-se dispor de um padrão, que pode ser aquele estabelecido para a principal linhagem criada. No entanto, destaca que é necessário adaptar esse padrão para as condições de criação da região e do produtor, pois, muitas vezes as empresas produtoras de material genético determinam o padrão a partir dos resultados médios dos $50 \%$ ou $25 \%$ melhores lotes produzidos, ou seja, em condições ideais de manejo e sanidade ou, então, com base em testes de desempenho.

\section{ANÁLISE DOS RESULTADOS}

Antes de analisar os resultados obtidos nesta pesquisa, na tabela 2 são apresentadas algumas estatísticas da UBA - União Brasileira de Avicultura, divulgada por Puperi (2002) na Reunião Plenária da União Brasileira de Avicultura no Nordeste em 2002. Trata-se de um quadro contendo a evolução média dos coeficientes de produção de frango de corte na avicultura brasileira, desde 1930 até 2001. Observa-se que, ao longo desses anos, o tempo de produção de um lote de frangos de corte diminuiu de 15 semanas (105 dias) para 42 dias, com uma conversão alimentar que diminuiu de 3,5 para 1,85 e um peso que aumentou de 1,5 quilos para 2,3 quilos. 
Tabela 2. Evolução média dos coeficientes de produção de frango de corte na avicultura brasileira

\begin{tabular}{|c|c|c|c|}
\hline ANO & $\begin{array}{c}\text { PESO FRANGO } \\
\text { VIVO }\end{array}$ & $\begin{array}{l}\text { CONVERSÃ } \\
0\end{array}$ & $\begin{array}{c}\text { IDADE DE ABATE } \\
\text { Semanas / Dias }\end{array}$ \\
\hline 1.930 & 1.500 & 3,50 & 15 Semanas \\
\hline 1.940 & 1.550 & 3,00 & 14 Semanas \\
\hline 1.950 & 1.800 & 2,50 & 10 Semanas \\
\hline 1.960 & 1.600 & 2,25 & 8 Semanas \\
\hline 1.970 & 1.700 & 2,15 & 7 Semanas \\
\hline 1.980 & 1.800 & 2,05 & 7 Semanas \\
\hline 1.984 & 1.860 & 2,00 & 47 Dias \\
\hline 1.988 & 1.940 & 2,00 & 47 Dias \\
\hline 1.994 & 2.050 & 1,98 & 45 Dias \\
\hline 1.998 & 2.150 & 1,95 & 45 Dias \\
\hline 2.000 & 2.250 & 1,88 & 43 Dias \\
\hline 2.001 & 2.300 & 1,85 & 42 Dias \\
\hline
\end{tabular}

Fonte: Puperi (2002)

A Tabela 3 mostra os resultados obtidos nesta pesquisa, contendo os índices técnicos, os preços de venda e os custos de produção do frango de corte. Os resultados técnicos dos integradores referem-se a valores que representam os resultados das integrações, ou seja, das várias granjas de seus integrados.

Observa-se que o peso médio da ave pronta para o abate foi maior entre os produtores independentes (em média 2,67 quilos) e os integradores (em média 2,65 quilos) do que entre os produtores integrados (2,48 quilos). O tempo médio de produção do lote é um pouco mais elevado entre os produtores independentes e integradores (cerca de 50 dias) do que entre os produtores integrados (cerca de 47 dias). Em comparação com a média brasileira em 2001 (Tabela 3), os pesos foram maiores, porém, as idades de retirada das aves para o abate também foram maiores, o que afeta negativamente a conversão alimentar.

A média de ganho de peso diário é maior entre os produtores independentes e integradores (54 gramas por dia), do que entre os produtores integrados (50 gramas por dia). Esta diferença pode ser decorrente de a maioria dos produtores independentes e integradores entrevistados trabalharem com a venda de frangos vivos, mercado que valoriza o peso da ave, enquanto que a maioria dos integrados entrevistados tem vínculo à integradores que possuem abatedouros industriais e vende a maior parcela de seus frangos abatidos, mercado onde o peso deixa de ser tão importante. No entanto, conforme descrito anteriormente, a maior média de 
ganho de peso diário apresentada pelos produtores independentes e integradores não significa maior eficiência, principalmente do ponto de vista do retorno econômico.

Quando o lote é apenas de aves fêmeas, normalmente, o tempo de produção do lote é menor do que quando o lote é misto ou exclusivamente de machos, podendo chegar a uma diferença de cerca de 10 dias. Esta diferença não foi considerada para fins desta análise, porém, pode estar influenciando estes resultados de peso médio da ave, tempo de produção do lote e média de ganho de peso diário.

A conversão alimentar é um pouco menor entre os produtores independentes e integrados (médias de 1,94 e 1,95, respectivamente), do que entre os integradores (média de 1,98). A conversão alimentar é um índice também utilizado em algumas integrações, como critério para estabelecer incentivos (bônus ou descontos) para os integrados. Observa-se que a conversão alimentar foi maior que a média da avicultura brasileira em 2001 (tabela 3).

Apesar de apresentar uma menor média na conversão alimentar, o grupo de produtores independentes mostra-se menos eficiente em relação à taxa de mortalidade (média de 4,4\%). Os integradores apresentam uma taxa de mortalidade média de $3,7 \%$ e os integrados de $3,5 \%$, o que mostra uma maior preocupação deste grupo em relação a este item. Uma vez que a maioria dos integrados é remunerada com base no fator de produção, que é inversamente proporcional à mortalidade, esta pode ser a justificativa para este grupo apresentar menor taxa de mortalidade.

A média do fator de produção foi mais elevada entre os produtores independentes (262) e entre os integradores $(258,6)$ do que entre os produtores integrados $(254,7)$. É necessário observar este índice com cautela, pois pode estar influenciado pela grande importância que os produtores independentes e integradores atribuem ao ganho de peso das aves. 
Tabela 3. Performance dos produtores

\begin{tabular}{|c|c|c|c|c|c|c|}
\hline Itens de performance & Grupos & $\begin{array}{l}\text { № } \\
\text { de }\end{array}$ & Média & Mínim & Máxim & $\begin{array}{l}\text { Desvio } \\
\text { Padrão }\end{array}$ \\
\hline \multirow{4}{*}{$\begin{array}{l}\text { Média de ganho de peso } \\
\text { diário (em gramas) }\end{array}$} & Independent & 06 & 54 & 50 & 55 & 2,1 \\
\hline & Integrador & 13 & 54 & 51 & 58 & 2,1 \\
\hline & Integrado & 15 & 50 & 40 & 53 & 3,7 \\
\hline & Total & 34 & 52 & 40 & 58 & 3,5 \\
\hline \multirow{3}{*}{$\begin{array}{l}\text { Taxa de mortalidade média } \\
(\%)\end{array}$} & Independent & 06 & 4,4 & 3 & 6 & 1,1 \\
\hline & Integrador & 13 & 3,7 & 2,5 & 5 & 0,8 \\
\hline & $\begin{array}{l}\text { Integrado } \\
\text { Total }\end{array}$ & $\begin{array}{l}17 \\
36\end{array}$ & $\begin{array}{l}3,5 \\
3,7\end{array}$ & $\begin{array}{l}2,5 \\
2,5\end{array}$ & $\begin{array}{l}5 \\
6\end{array}$ & $\begin{array}{l}0,6 \\
\mathbf{0 , 8}\end{array}$ \\
\hline \multirow{4}{*}{ Conversão alimentar média } & Independent & 06 & 1,94 & 1,7 & 2,1 & 0,1 \\
\hline & Integrador & 13 & 1,9 & 1,87 & 2,1 & 0,0 \\
\hline & Integrado & 17 & 8 & 1,9 & 2 & 8 \\
\hline & Total & 36 & 1,96 & 1,7 & 2,1 & 0,0 \\
\hline \multirow{4}{*}{$\begin{array}{l}\text { Fator de produção médio } \\
\text { por lote }\end{array}$} & Independent & 04 & 262,0 & 255 & 270 & 7,2 \\
\hline & Integrador & 13 & 258,6 & 230 & 295 & 20 \\
\hline & Integrado & 17 & 254,7 & 240 & 273 & 4 \\
\hline & Total & 34 & 257,1 & 230 & 295 & 14 \\
\hline \multirow{4}{*}{$\begin{array}{l}\text { Tempo médio de produção } \\
\text { (número de dias) }\end{array}$} & Independent & 05 & 49,6 & 46 & 52 & 2,3 \\
\hline & Integrador & 11 & 49,5 & 48 & 55 & 1,9 \\
\hline & Integrado & 17 & 46,8 & 40 & 56 & 3,7 \\
\hline & Total & 33 & 48,1 & 40 & 56 & 3,2 \\
\hline \multirow{4}{*}{$\begin{array}{l}\text { Peso médio da ave pronta } \\
\text { abate (em quilos) }\end{array}$} & Independent & 06 & 2,67 & 2,4 & 3 & 0,2 \\
\hline & Integrador & 13 & 2,65 & 2,4 & 3 & 0,1 \\
\hline & Integrado & 17 & 2,48 & 2,2 & 3 & 0,2 \\
\hline & Total & 36 & 2,57 & 2,2 & 3 & 0,2 \\
\hline
\end{tabular}

Para atender ao objetivo deste trabalho, foi realizado um teste de hipótese buscando verificar se as diferenças entre as performances dos produtores que operam com os diferentes mecanismos de coordenação são significantes ou não. Optou-se pela comparação apenas entres os grupos dos produtores independentes que apresentaram os resultados de performance de suas granjas próprias, caracterizando o uso da coordenação via hierarquia; e dos integrados, cuja atividade de criação de frango de corte é coordenada por meio de parcerias (formas híbridas) através da informação.

O grupo dos integradores não foi incluído nesta análise, pois seus resultados de performance referem-se ao conjunto das operações, tanto de granjas próprias como das granjas dos integrados. Formulou-se, portanto, a seguinte hipótese: 
Hipótese:

HO - Não há relações entre os diferentes mecanismos de coordenação das atividades e a performance dos produtores de frango de corte do Estado de Pernambuco.

H1 - Há relações entre os diferentes mecanismos de coordenação das atividades e a performance dos produtores de frango de corte do Estado de Pernambuco.

A Tabela 4 mostra que o Teste Mann-Whitney $U$ revelou diferença estatisticamente significante na associação entre os diferentes mecanismos de coordenação, aqui divididos nos grupos de produtores independentes e de produtores integrados, e a média de ganho de peso diário (nível de significância de 1\%). Em relação à taxa de mortalidade e ao tempo médio de produção do lote, as diferenças entre as médias para os dois grupos de produtores são marginalmente significantes (níveis de significância de 8\% e 6\%, respectivamente).

Apesar dessas variáveis influenciarem o fator de produção, não foi apresentada diferença estatisticamente significante entre as médias desta variável para os dois grupos de produtores, pois outras variáveis, como a conversão alimentar, também influenciam este índice.

Observa-se que a escolha do mecanismo de coordenação das atividades não afeta totalmente a performance dos produtores entrevistados, como havia sido identificado em trabalhos como o de Miranda (1997). No entanto, cabe ressaltar que, nesta análise, não foram considerados fatores como o grau de formalidade das atividades desenvolvidas pelos produtores e que a seleção da amostra não foi feita de forma aleatória, o que prejudica a análise e torna inviável a realização de inferências sobre todo o setor avícola de Pernambuco. 
Tabela 4. Relações entre os mecanismos de coordenação e a performance dos produtores

\begin{tabular}{|c|c|c|c|c|c|c|c|}
\hline \multirow[b]{2}{*}{ Performance } & \multicolumn{3}{|c|}{ Produtores Independentes } & \multicolumn{3}{|c|}{ Produtores Integrados } & \multirow{2}{*}{$\begin{array}{l}\text { Teste Mann- } \\
\text { Whitney U } \\
\text { (Significância) }\end{array}$} \\
\hline & $\begin{array}{l}\text { № de } \\
\text { Casos }\end{array}$ & Média & $\begin{array}{l}\text { Desvio } \\
\text { Padrão }\end{array}$ & $\begin{array}{l}\text { № de } \\
\text { Casos }\end{array}$ & Média & $\begin{array}{l}\text { Desvio } \\
\text { Padrão }\end{array}$ & \\
\hline $\begin{array}{l}\text { Média de } \\
\text { ganho de peso } \\
\text { diário }\end{array}$ & 06 & 53,5 & 2,07 & 15 & 49,4 & 3,65 & 0,02 \\
\hline $\begin{array}{l}\text { Taxa de } \\
\text { mortalidade } \\
\text { média }\end{array}$ & 06 & 4,4 & 1,11 & 17 & 3,5 & 0,63 & 0,08 \\
\hline $\begin{array}{l}\text { Conversão } \\
\text { alimentar } \\
\text { média }\end{array}$ & 06 & 1,94 & 0,17 & 17 & 1,94 & 0,05 & 0,57 \\
\hline $\begin{array}{l}\text { Fator de } \\
\text { produção } \\
\text { médio por lote }\end{array}$ & 06 & 262,0 & 7,16 & 17 & 254,7 & 10,92 & 0,24 \\
\hline $\begin{array}{l}\text { Tempo médio } \\
\text { de produção } \\
\text { do lote }\end{array}$ & 06 & 49,6 & 2,30 & 17 & 46,8 & 3,67 & 0,06 \\
\hline $\begin{array}{l}\text { Peso médio da } \\
\text { ave pronta } \\
\text { para o abate }\end{array}$ & 06 & 2,67 & 0,23 & 17 & 2,5 & 0,21 & 0,11 \\
\hline
\end{tabular}

\section{CONSIDERAÇÕES FINAIS}

Com a análise dos resultados, verifica-se que a escolha do mecanismo de coordenação é um fator que influencia, ainda que parcialmente, o desempenho dos produtores de frango de corte do Estado de Pernambuco. Provavelmente, esta influência poderia ser ainda maior, caso o setor fosse ainda mais organizado, mais formalizado e se houvesse uma troca de informações ainda mais intensa entre os produtores desta cadeia produtiva.

O critério de seleção da amostra, por conveniência, prejudica a análise dos resultados e não permite a generalização das conclusões. Esta limitação é ainda mais relevante em relação aos resultados obtidos dos integrados, pois o universo deste grupo é bastante amplo e de difícil acesso. 


\section{REFERÊNCIAS}

ANUALPEC 2001. ANUÁRIO DA PECUÁRIA BRASILEIRA. São Paulo, FNP Consultoria \& Comércio, 2001, p.237-254.

AZEVEDO, J.H. 1997. Como abrir seu próprio negócio. Brasília, Sebrae, 1997.

BARUT, M.; FAISST, W. e KANET, J.J. 2002. Measuring supply chain coupling: an information system perspective. European Journal of Purchasing \& Supply Management.

BECCERRA, M. e GUPTA, A.K. 1999. Trust within the organization: Integrating the trust literature with agency theory and transaction costs economics. Public Administration Quarterly, 23:177- 203.

BILLINGTON, C. 1994. Strategic Supply Chain Management. OR/MS Today, April: 2027.

CHRISTOPHER, M. 1999. Logística e gerenciamento da cadeia de suprimentos: Estratégias para redução de custos e melhoria dos serviços. São Paulo, Pioneira.

COSTA, A.D. 1999. Avicultura brasileira no limiar do século XXI. Tuiuti: Ciência e Cultura, 13:22- 39.

FURLANETTO, E.L. 2000. Coordenação pela cadeia produtiva e a geração de inovações. In: SIMPÓSIO DE GESTÃO DA INOVAÇÃO TECNOLÓGICA, 21, 2000, São Paulo. Anais eletrônicos...São Paulo, USP/PGT, p. 1-15.

JANK, M.S. 1996. Competitividade do agribusiness brasileiro: discussão teórica e evidências no sistema carnes. São Paulo, SP. Tese de doutorado. USP.

LAZZARINI, S.G. e GIORDANO, S.R. 1996. Tecnologia genética e inovação: um estudo de caso no agribusiness. In: SIMPÓSIO DE GESTÃO DA INOVAÇÃO TECCNOLÓGICA, 19, 1996, São Paulo. Anais... São Paulo, USP/PGT/FIA/PACTO, p. 1083-1096.

MACHADO, R.T.M. 1998. Tecnologia da informação e competitividade em sistemas agroindustriais: um estudo exploratório. Revista Brasileira de Agroinformática, 1(1):6676.

MACHADO, R.T.M. 1996. Aplicação da tecnologia da informação na Sadia. In: J. MARCOVITCH (org.), Tecnologia da informação e estratégia empresarial. São Paulo, FEA/USP, p. 1-12.

MANUAL DE MANEJO DE FRANGOS. 2000. São Paulo, Agroceres. 
MARQUES, D.B. 2000. Desempenho competitivo, capacidades diferenciadoras e posicionamento competitivo na estrutura da indústria pernambucana de frango de corte: um estudo de caso. Recife, PE. Dissertação de mestrado. UFPE.

MEIRA, J.M. de. 2002. O papel da troca de informações interorganizacionais e da escolha dos mecanismos de coordenação na performance da cadeia de produção avícola de Pernambuco. Recipe, PE. Dissertação de mestrado. UFPE, $111 \mathrm{p}$.

MENDES, A.A. 1989. Controles e registros e métodos de avaliação do desempenho de frangos de corte. In: A.A. MENDES, Curso de atualização em manejo de frangos de corte. Campinas, APINCO.

NASCIMENTO, E.R. do. 1986. Como criar frangos de corte. Rio de Janeiro, Ediouro.

MIRANDA, L.C. 2002. Gerenciamento de cadeia de valor. In: P. SCHIMIDT (org.), Controladoria: agregando valor para a empresa. Porto Alegre, Bookman, p. 201-212.

MIRANDA, L.C. 1997. The Role of Interfirm Information Exchange and Choice of Coordination Mechanism on Performance in the U.S. Pork Supply Chain. Urbana, Illinois. Ph.D. Dissertation. University of Illinois (Urbana-Champaign).

POIRIER, C.C. e REITER, S.E. 1996. Supply chain optimization: building the strogest total business network. San Francisco, Berrett-Koehler.

PORTER, M.E. 1986. Estratégia competitiva: técnicas para análise de indústrias e da concorrência. $7^{\text {a }}$ ed., Rio de Janeiro, Campus. 